\title{
Antitumor immune activity by chemokine CX3CL1 in an orthotopic implantation of lung cancer model in vivo
}

\author{
JI-YE KEE ${ }^{1}$, YOSHIHISA ARITA ${ }^{1}$, KANNA SHINOHARA ${ }^{1}$, YASUKATA OHASHI ${ }^{1}$, \\ HIROAKI SAKURAI $^{1,3}$, IKUO SAIKI ${ }^{1}$ and KEIICHI KOIZUMI ${ }^{1,2}$ \\ Divisions of ${ }^{1}$ Pathogenic Biochemistry and ${ }^{2}$ Kampo Diagnostics, Institute of Natural Medicine, \\ ${ }^{3}$ Department of Cancer Cell Biology, Graduate School Medicine and Pharmaceutical Sciences, \\ University of Toyama, Toyama 930-0194, Japan
}

Received May 18, 2012; Accepted July 17, 2012

DOI: $10.3892 / \operatorname{mco} .2012 .30$

\begin{abstract}
Due to their chemoattractant properties stimulating the accumulation of infiltrating immune cells in tumors, chemokines are known to have antitumor effects. Fractalkine, a unique $\mathrm{CX} 3 \mathrm{C}$ chemokine, is expressed in activated endothelial cells, while its receptor, CX3CR1, is expressed in cytolytic immune cells, such as natural killer cells, monocytes and some $\mathrm{CD}^{+} \mathrm{T}$ cells. The biological properties of cancer cells are affected by the implantation organ and differences in immune systems, requiring cancer implantation in orthotopic organs in an in vivo experiment. To develop new therapy strategies for lung cancer, an animal model reflecting the clinical features of lung cancer was previously established. This study aimed to determine whether CX3CL1-induced biological functions should be used for immune cell-based gene therapy of lung cancer in the orthotopic implantation model. An orthotopic intrapulmonary implantation of CX3CL1-stable expression in mouse lung cancer (LLC-CX3CL1) was performed to analyze growth. Results showed a significant decrease in tumor growth in the lung compared to the control cells (LLC-mock). Furthermore, the antitumor effects of CX3CL1 were derived from natural killer cell activities in the depletion experiment in vivo. Therefore, CX3CL1 has the potential of a useful therapeutic target in lung cancer.
\end{abstract}

\section{Introduction}

Treatment outcomes of lung cancer are relatively poor and have not improved significantly in the past 20 years. In addition to common unresectable cases, resectable cases require systemic chemotherapy at a certain stage. Although improvement in the outcomes of chemotherapy in lung cancer has been

Correspondence to: Dr Keiichi Koizumi, Division of Kampo Diagnostics, Institute of Natural Medicine, University of Toyama, 2630 Sugitani, Toyama 930-0194, Japan

E-mail: kkoizumi@inm.u-toyama.ac.jp

Key words: chemokine, CX3CL1, gene therapy, orthotopic implantation gradually observed, they remain unsatisfactory in circumstances whereby medication efficacy is only $2-3 \%$. Therefore, gene therapy is clinically expected as the treatment strategy is different from that of the existing chemotherapy or radiation therapy. Subcutaneous implantation is widely practiced since cancer growth is easily observed. However, studies have shown that the biological behavior of cancer cells is influenced by the implantation site (1), and that the orthotopic implantation of human tumor cells into relevant organs of nude mice provides an in vivo model to study the biology and therapy of these cells $(1,2)$.

On the other hand, chemokines are a family of small cytokines that primarily induce the directed migration of hematopoietic cells when bound to their seven-transmembrane, $\mathrm{G}$ protein-coupled receptors $(3,4)$. Chemokines are attractive candidates for immune cell-based approaches to cancer gene therapy, as they function as chemoattractants for several immune effector cell types. CX3CL1 (also known as fractalkine) is a unique chemokine that functions as an adhesion and chemotactic molecule towards its receptor CX3CR1-expressing cells. Although chemokines activate adhesion molecules, such as integrins, to bind to target cells or the cellular matrix, the interaction of transmembrane CX3CL1-CX3CR1 strongly induces cell-to-cell contact in an adhesion molecule-independent manner $(5,6)$. This study was conducted to examine the efficacy of mouse CX3CL1 for gene therapies by employing an orthotopic transplantation model of mouse lung cancer cells, a model reflecting cancer growth in the lung (7).

\section{Materials and methods}

Cell culture and transfection. Mouse lung cancer cells, Lewis lung carcinoma (LLC), were maintained in EMEM containing $10 \%$ fetal bovine serum (FBS), 2 mM L-glutamine, $100 \mathrm{U} / \mathrm{ml}$ penicillin and $100 \mu \mathrm{g} / \mathrm{ml}$ streptomycin. Cultures were kept at $37^{\circ} \mathrm{C}$ in a humidified atmosphere of $5 \% \mathrm{CO}_{2} / 95 \%$ air. LLC cells were transfected by Nucleofector ${ }^{\mathrm{TM}}$ (Amaxa Biosystems, Gaithersburg, MD, USA). Expression vectors (pIRES2-EGFP vector; Takara Bio, Inc., Shiga, Japan) for mouse membrane-bound CX3CL1, pIRES2-EGFP-CX3CL1 were used. DNA was adjusted to $1 \mu \mathrm{g}$ with empty vectors. 
Subsequent to transfection, EGFP-positive LLC cells were sorted using FACSCalibur (BD Biosciences, Franklin Lakes, $\mathrm{NJ}$, USA) and cultured at $37^{\circ} \mathrm{C}$ with the antibiotic $\mathrm{G} 148$ (Invitrogen, Carlsbad, CA, USA). CX3CL1-stable expression cells (LLC-CX3CL1) and control cells (LLC-mock) were also cultured. CX3CR1-stable expression cells (L-CX3CR1) were maintained in RPMI-1640 supplemented with 10\% FBS and antibiotics.

Animals. Specific pathogen-free C57BL/6 mice (7-week-old females) were purchased from Japan SLC, Inc. (Hamamatsu, Japan). The mice were maintained in the Laboratory for Animal Experiments of the Institute of Natural Medicine, Toyama Medical and Pharmaceutical University, Japan, under laminar air flow conditions. This study was conducted in accordance with the standards established by the Guidelines for the Care and Use of Laboratory Animals of the Toyama University.

Reverse transcription-polymerase chain reaction (RT-PCR). RT-PCR was performed as previously described (8). Briefly, total RNA was extracted using an RNeasy mini kit (Qiagen, Hilden, Germany), according to the manufacturer's instructions. First-strand cDNA was prepared from an RNA template (2 $\mu \mathrm{g})$ using an oligo(dT)18 primer and SuperScript II reverse transcriptase (Invitrogen, Carlsbad, CA, USA). Reverse transcription was performed at $42^{\circ} \mathrm{C}$ for $50 \mathrm{~min}$ and then at $70^{\circ} \mathrm{C}$ for $15 \mathrm{~min}$. PCR amplification was performed using the Takara Ex Taq HS PCR kit (Takara Bio, Inc.) under the following conditions: 26 cycles of denaturation at $94^{\circ} \mathrm{C}$ for $30 \mathrm{sec}$, annealing at $60^{\circ} \mathrm{C}$ for $60 \mathrm{sec}$, and extension at $72^{\circ} \mathrm{C}$ for $60 \mathrm{sec}$. The primers were verified to yield the expected products under the indicated conditions. PCR products were electrophoresed on $1.5 \%$ agarose gels and stained with ethidium bromide. The primer sequences were: GAPDH, sense: 5'-TGAAGGTCGGAGTCAACGGATTTGGT-3' and antisense: 5'-CATGTGGGCCATGAGGTCCACCAC-3'; mouse CX3CL1, sense: 5'-GAGCATTGGAAGTTTTGAGG-3' and antisens: 5'-GGTTGAAGGTGAAGTAGTGGA-3'.

Fluorescence-activated cell sorting (FACS) analysis. LLC-CX3CL1 or LLC-mock cells were fixed with $4 \%$ labeled with paraformaldehyde, and incubated with anti-mouse CX3CL1 (provided by the Kan Research Institute, Kobe, Japan). Subsequent to incubation, the cells were washed three times with PBS, then stained with PE anti-Armenian and Syrian hamster immunoglobulin G (IgG) as the second antibody. FITC-labeled cells were then analyzed by flow cytometric analysis using FACSCalibur (BD Biosciences).

Migration assay. The migration assay was performed in Transwell cell culture chambers (Corning Incorporated Life Sciences, Tewksbury, MA, USA), as reported previously, with some modifications (9). Polyvinylpyrrolidone-free polycarbonate (PVFP) filters $(8.0 \mu \mathrm{m}$ pore size; Nuclepore, Pleasanton, CA, USA) were pre-coated with $1 \mu \mathrm{g}$ fibronectin (Asahi Technoglass Co., Tokyo, Japan) on the lower compartment. LLC-CX3CL1 or LLC-mock cell suspension $\left[1 \times 10^{5}\right.$ cells $/ 100 \mu 1$ in EMEM with $0.1 \%$ bovine serum albumin (BSA)] was added to the upper compartment and incubated for $4 \mathrm{~h}$ at $37^{\circ} \mathrm{C}$. Cells that invaded the lower surface were counted under a microscope in five pre-determined fields at x400 magnification.

Adhesion assay. The adhesion assay was performed as described previously, with some modifications (10). Triplicate wells of 96-well plates were coated with $1 \mu \mathrm{g}$ fibronectin. LLC-CX3CL1 or LLC-mock cells $\left(1 \times 10^{4}\right.$ cells $/ 100 \mu \mathrm{l}$ in EMEM with $0.1 \% \mathrm{BSA}$ ) were incubated for $25 \mathrm{~min}$ at $37^{\circ} \mathrm{C}$. Cells that adhered to the well were counted under the microscope in five pre-determined fields at x400 magnification.

ELISA. Conditioned media of LLC-CX3CL1 or LLC-mock cells were collected in $1.5 \mathrm{ml}$ tubes, centrifuged at 2,000 rpm for $5 \mathrm{~min}$ to remove cell debris, and kept at $-80^{\circ} \mathrm{C}$ until assay. Assays were performed in a mouse CX3CL1 ELISA system (R\&D Systems Inc., Minneapolis, MN, USA).

Chemotaxis assay. Chemotaxis assay was performed as described previously, with some modifications (11). LLC-CX3CL1 or LLC-mock cells were cultured in EMEM with $0.1 \%$ BSA for $24 \mathrm{~h}$ and conditioned media were collected. L-CX3CR1 cells labeled with DiA (Invitrogen) were applied to the upper wells of Transwell cell culture chambers of $8 \mu \mathrm{m}$ pore size (Corning Incorporated Life Sciences) in $100 \mu 1$ assay buffer (RPMI-1640 with 10 mM HEPES, pH 7.4, 1\% $\mathrm{BSA})$. Aliquots of conditioned media were pre-treated with or without anti-mouse CX3CL1 or control IgG for $30 \mathrm{~min}$ at $37^{\circ} \mathrm{C}$ and then applied to the lower wells in a volume of $350 \mu 1$. After $4 \mathrm{~h}$ at $37^{\circ} \mathrm{C}$, cells that migrated into lower wells were lysed with $0.2 \%$ Triton X-100 in $20 \%$ ethanol and quantitated by fluorescence intensity measurement (excitation, $595 \mathrm{~nm}$; emission, $485 \mathrm{~nm}$ ).

Orthotopic implantation. The orthotopic intrapulmonary implantation of LLC cells was performed as described previously, with some modifications (7). Briefly, log-phase cell cultures of LLC-CX3CL1 or LLC-mock cells were suspended at a cell density of $2.5 \times 10^{5}$ cells $/ \mathrm{ml}$ in PBS containing $500 \mu \mathrm{g} / \mathrm{ml}$ Matrigel. Animals $(\mathrm{n}=6)$ were anesthetized and a small skin incision was made to the left chest wall $(\sim 5 \mathrm{~mm}$ in length). A 29-gauge needle attached to a 0.5 -ml insulin syringe was inserted directly through the intercostal space into the lung to a depth of $3 \mathrm{~mm}$. Cells $\left(5 \times 10^{5}\right)$ were re-suspended in $20 \mu \mathrm{l}$ of PBS containing $10 \mu \mathrm{g}$ Matrigel, and injected into the lung parenchyma. To deplete the NK cells in vivo, mice $(n=6)$ were intraperitoneally injected with $200 \mu \mathrm{l}$ anti-asialo GM1 antibody twice a week.

Statistical analysis. The significance of differences between groups was determined by applying the two-tailed Student's t-test. $\mathrm{P}<0.05$ were considered to indicate a statistically significant difference. The means and SDs were calculated for all variables

\section{Results}

Stable expression of mouse CX3CL1 in mouse lung cancer cells. We initially intended to obtain CX3CL1 stable-expression polyclonal LLC cells lines (LLC-CX3CL1) by combining 
A

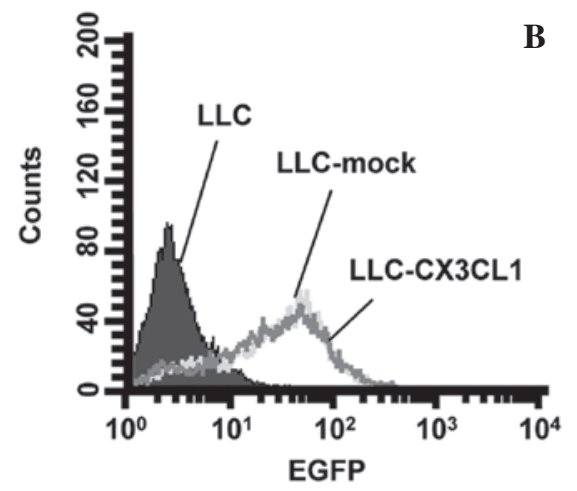

C

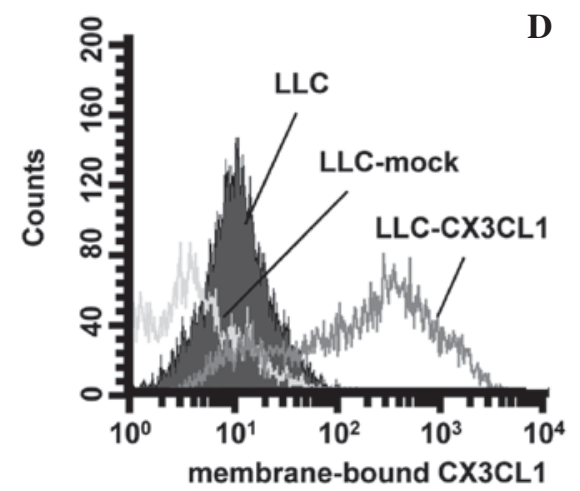

B
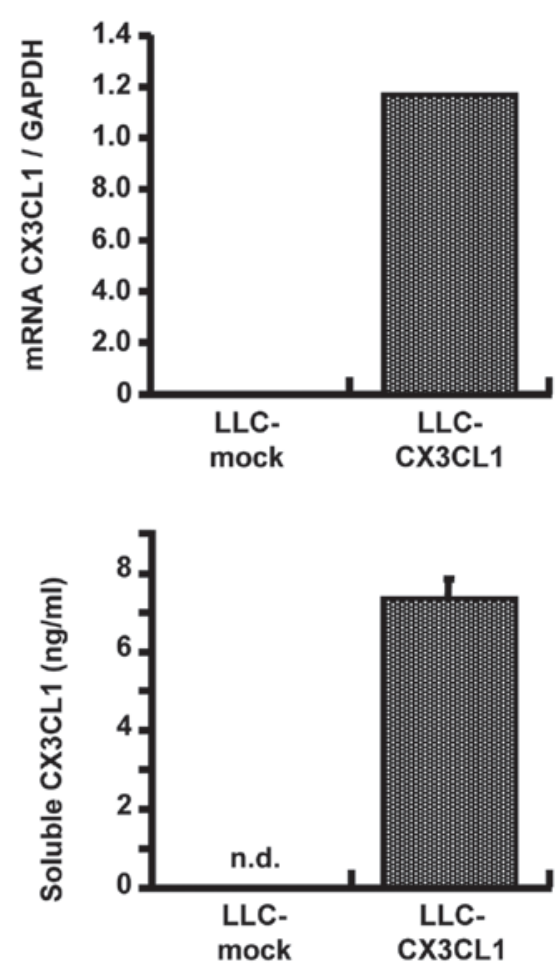

Figure 1. CX3CL1 expression of CX3CL1 gene-transfected cancer cells is shown. (A) After sorting EGFP-positive LLC cells using the FACSCalibur, (B) CX3CL1 transcript in LLC cells transfected with pIRES2-EGFP-CX3CL1 or pIRES2-EGFP-mock vector was detected by RT-PCR. Expression of membrane-bound and soluble CX3CL1 of sorted LLC cells (LLC-CX3CL1 and LLC-mock) were detected by (C) FACS and (D) ELISA, respectively.

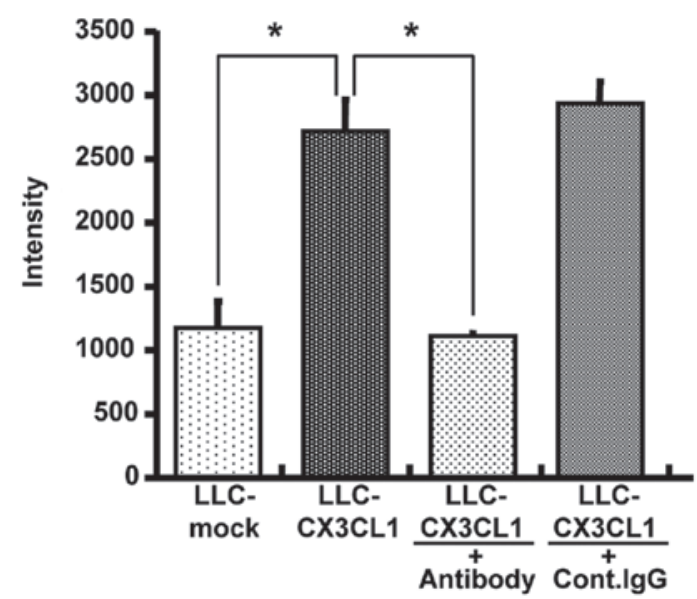

Figure 2. Chemotactic activity of CX3CL1 secreted by LLC-CX3CL1 is shown. LLC-CX3CL1 supernatants were added to the lower wells with or without neutralizing anti-CX3CL1 Ab. DiA-labeled L-CX3CR1 cells were placed in the upper compartments of Transwell chambers. After $4 \mathrm{~h}$ incubation, cells migrated into lower wells were lysed and quantitated by fluorescence intensity measurement.

antibiotic selection and flow cytometric sorting to obtain an index of the EGFP expression (Fig. 1A). LLC-CX3CL1 was found to express mRNA of mouse CX3CL1 (Fig. 1B). Moreover, as CX3CL1 has two phenotypes, flow cytometry and western blotting confirmed a higher expression of membranebound and soluble CX3CL1 in LLC-CX3CL1 compared to LLC-mock cells (Fig. 1C and D). Gene introduction into cells often generates various changes in the characteristics compared to the control cells. No changes were observed regarding the cell proliferation, adhesion and migration towards the fibronectin of LLC-CX3CL1, when compared with CX3CL1-mock cells (data not shown).

Chemotactic activity of LLC-CX3CL1-generated CX3CL1. Given that LLC-CX3CL1 cells were stably expressed in mouse membrane-bound and soluble CX3CL1, and their properties were not different from those of CX3CL1-mock cells, polyclonal LLC cell line-generated CX3CL1 was verified to be biologically active. As a result of migration assay-induced chemotactic activity using L-CX3CR1 cells in culture supernatants, the supernatant of LLC-CX3CL1 significantly induced L-CX3CR1 as well as anti-mouse CX3CL1 cell migration, although the control $\operatorname{IgG}$ antibody did not completely neutralize chemotactic activity (Fig. 2).

Antitumor effect of CX3CL1 in the orthotopic transplantation of lung cancer models. The effect of CX3CL1-induced tumor growth inhibition was examined using orthotopic transplantation models. Seventeen days after LLC/CX3CL1 and LLC-mock were transplanted into the left lung of a mouse, the weight of the solid tumor was examined. The result showed a $65 \%$ inhibition of tumor growth compared to LLC-mock (Fig. 3).

Elucidation of CX3CL1-induced antitumor effects by immune cells. Anti-asialo GM1 antibody was used for NK cell depletion in vivo. Initially, FACS analysis was used to determine whether NK1.1-positive NK cells are eliminated by administering $200 \mu \mathrm{g}$ anti-asialo GM1 antibody via the tail vein to 
A
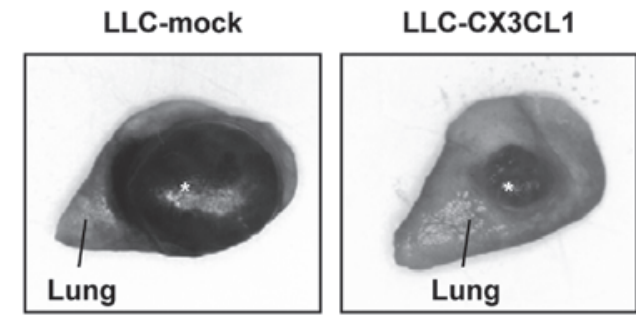

B

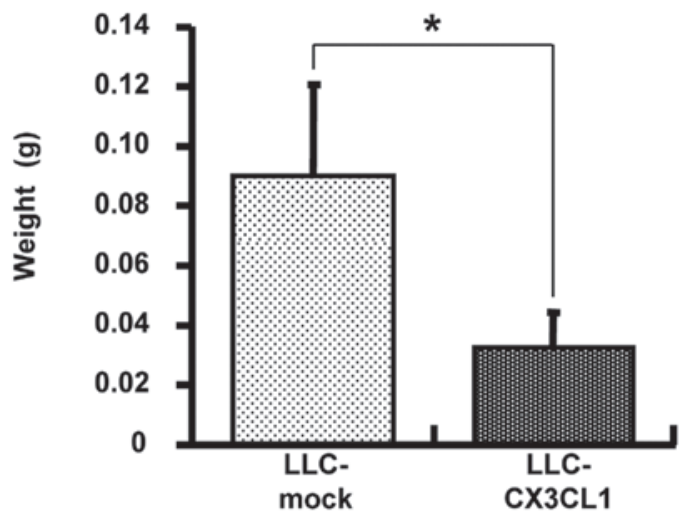

C

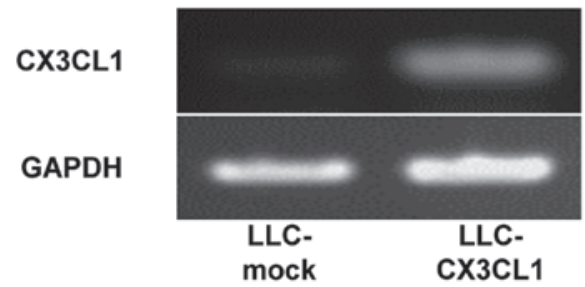

Figure 3. Effect of CX3CL1 on orthotopic intrapulmonary implantation of cancer growth is shown. LLC-CX3CL1 and LLC-mock cells $\left(5 \times 10^{5}\right)$ suspended in $20 \mu 1$ PBS containing $10 \mu \mathrm{g}$ Matrigel were injected into lung parenchyma. (A) Macroscopic observation of the resected lung on Day 17 after the orthotopic implantation of these cells is shown. (B) The weight of cancer at the implanted site was measured on Day 17 after implantation, ${ }^{*} \mathrm{P}<0.05$. (C) CX3CL1 mRNA expression of implanted cells was detected on day 17 after implantation.

a C57BL/6 mouse twice with in a distance of 2 days (data not shown). In the non-treated group, LLC/CX3CL1 growth was significantly inhibited compared to the LLC-mock in the orthotopic intrapulmonary implantation of LLC cells (Fig. 4). In the depletion groups, the inhibition of LLC/CX3CL1 growth was suppressed. By contrast, the growth suppressive effects of CX3CL1 against LLC were affected by neither CD4 nor CD8 depletion (data not shown). These results suggest that NK cells contributed to the marked antitumor effect of CX3CL1.

\section{Discussion}

Chemokines are molecules attractive for cancer gene therapy (12), a method categorized as a cell-based cancer immunotherapy due to the involvement of chemokine-mediated immune cell chemotaxis, as well as the angiostatic activity of some chemokines (13). CX3CL1 is a type I transmembrane ligand expressed in activated vascular endothelial and dendritic cells (14-16). The secreted CX3CL1 is chemotactic for chemokine receptor, CX3CR1-expressing cells. The

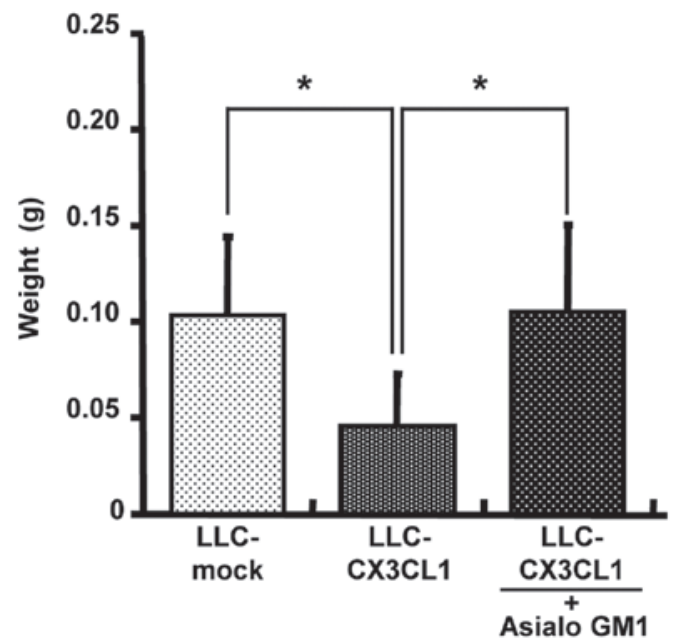

Figure 4. Growth of LLC-CX3CL1 with or without the depletion of NK cells is shown. After the orthotopic implantation of LLC-CX3CL1 and LLC-mock cells to deplete NK cells in vivo, mice $(n=6)$ intraperitoneally injected with anti-asialo GM1 antibody were used for NK cell depletion in vivo, twice a week. The weight of cancer at the implanted site was measured on Day 17 after implantation, ${ }^{*} \mathrm{P}<0.05$.

membrane form adheres to chemo-attracted cells, resulting in the interaction of dendritic cells, monocytes, $\mathrm{T}$ cells and natural killer cells (NK cells) locally $(5,6)$. Initially, the chemotactic activity of CX3CL1 secreted by LLC-CX3CL1 stably expressing CX3CL1 was confirmed (Fig. 2). The secreted form of CX3CL1 is produced by a disintegrin-like metalloproteinase (ADAM)-mediated shedding of the extracellular chemokine domain, acting as a chemoattractant of mainly NK cells through CX3CR1 $(17,18)$.

In this experiment, pIRES2-EGFP-encoded mouse CX3CL1 was used as the full-length transmembrane type, resulting in an efficient production of soluble CX3CL1 through cleavage at the membrane site by the ADAM family. Previous studies have showed that the biological behavior of cancer cells is influenced by the implantation organ (1), while properties of the immune system are also known to be different in each organ. A useful model for a solitary pulmonary tumor has previously been established by the intrapulmonary implantation of LLC cells in syngeneic immunocompetent mice (7,19-21). This model has the advantage of being simple and easy regarding the implantation procedure with a small skin incision at a pre-determined site followed by direct puncturing through the intercostal space to the lung parenchyma, without thoracotomy or intubation. Marked lung cancer regression was observed in LLC-CX3CL1 when compared to tumors comprising control cells (LLC-mock) (Fig. 3). Given the lack of cell functions, as well as the cell proliferation, adhesion and migration of LLC/CX3CL1 and LLC-mock (data not shown), these results suggest that the growth inhibition effect in vivo respresents the antitumor effect depending on CX3CL1. CX3CL1 secreted from LLC/CX3CL1 in vitro generates the migration of CX3CR1-positive lymphocytes (Fig. 2). Therefore, to investigate the immune cell functions involved in the antitumor effects of CX3CL1, an in vivo depletion analysis was carried out using specific antibodies against CX3CR1positive immune cells ( $\mathrm{NK}, \mathrm{CD} 8^{+} \mathrm{T}$ and $\mathrm{CD} 4^{+} \mathrm{T}$ cells), in the 
orthotopic intrapulmonary implantation of LLC cells. The CX3CL1-dependent antitumor effect was derived from NK cell activities (Fig. 4).

In clinical studies, leukocyte accumulation in cancers directed by cancer cell-derived chemokines are crucial in cancer progression and metastasis. Chemokine expression was detected in several cancers, while cancer cell-derived chemokines were responsible for the infiltration of various types of leukocytes, mainly macrophages, into these cancers $(22,23)$. CCL5 [also termed regulated on activation, normal T-cell expressed and secreted, (RANTES)] and CCL2 [also known as monocyte chemotactic protein-1, (MCP-1)] are chemokines frequently observed in cancer. In breast cancer, a lower CCL2 expression was correlated with longer relapse-free survival and decreased tumor-associated macrophage (TAM) (24), while a higher level of CCL5 expression was associated with an increase of TAM and lymph node metastasis (25). In contrast to CCL2 and CCL5, a highlevel expression of chemokine CXCL16 by tumor cells has recently been reported to correlate with a good prognosis and increased $\mathrm{CD}^{+} \mathrm{T}$ as well as $\mathrm{CD}^{+} \mathrm{T}$ cells in CRC (26). In addition, CX3CL1 is correlated with a better prognosis and an increased number of CX3CR1-positive $\mathrm{CD} 8^{+} \mathrm{T}$ and $\mathrm{NK}$ cells migrated into primary cancer in several cancers, such as CRC (27) or gastric adenocarcinoma (28). Although these clinical studies do not comprise cancer gene therapy, they indicate that the accumulation of CX3CR1-positive immune cells in primary cancer results in antitumor activity. Therefore, the finding that a cancer gene therapy strategy supports the accumulation of NK cells by CX3CL1, might be an effective therapeutic approach towards lung cancer, although the correlation of lung cancer-derived CX3CL1, migrated NK cells and good prognosis need to be further investigated.

\section{Acknowledgements}

The authors would like to thank Drs Takashi Nakayama and Osamu Yoshie, (Department of Microbiology and SORST, Kinki University School of Medicine, Osaka, Japan) for their helpful advice and technical support. This study was supported by a Grant-in-Aid for Young Scientists (B) (no. 15790089), Grants-in-Aid for Cancer Research (nos. 16022224 and 16023225), the 21st Century COE Program from the Ministry of Education, Culture, Sports, Science and Technology and a grant for Cooperative Link of Unique Science and Technology for Economy Revitalization (CLUSTER) from the Ministry of Education, Culture, Sports, Science and Technology of Japan.

\section{References}

1. Fidler IJ: Rationale and methods for the use of nude mice to study the biology and therapy of human cancer metastasis. Cancer Metastasis Rev 5: 29-49, 1986.

2. McLemore TL, Egglestone LC, Shoemaker RH, Abbott BJ, Bohlman ME, Liu MC, Fine DL, Mayo JG and Boyd MR: Comparison of intrapulmonary, percutaneous, intrathoracic, and subcutaneous models for the propagation of human pulmonary and non-pulmonary cancer cell lines in athymic nude mice. Cancer Res 48: 2880-2886, 1988.

3. Yoshie O, Imai $\mathrm{T}$ and Nomiyama H: Novel lymphocyte-specific CC chemokines and their receptors. J Leukoc Biol 62: 634-644, 1997.
4. Yoshie $\mathrm{O}$, Imai $\mathrm{T}$ and Nomiyama $\mathrm{H}$ : Chemokines in immunity. Adv Immunol 78: 57-110, 2001.

5. Imai T, Hieshima K, Haskell C, Baba M, Nagira M, Nishimura M, Kakizaki M, Takagi S, Nomiyama H, Schall TJ and Yoshie O: Identification and molecular characterization of fractalkine receptor CX3CR1, which mediates both leukocyte migration and adhesion. Cell 91: 521-530, 1997.

6. Umehara H, Bloom E, Okazaki T, Domae N and Imai T: Fractalkine and vascular injury. Trends Immunol 22: 602-607, 2001.

7. Doki Y, Murakami K, Yamaura T, Sugiyama S, Misaki T and Saiki I: Mediastinal lymph node metastasis model by orthotopic intrapulmonary implantation of Lewis lung carcinoma cells in mice. Br J Cancer 79: 1121-1126, 1999.

8. Nakamura ES, Koizumi K, Kobayashi M and Saiki I: Inhibition of lymphangiogenesis-related properties of murine lymphatic endothelial cells and lymph node metastasis of lung cancer by the matrix metalloproteinase inhibitor MMI270. Cancer Sci 95: 25-31, 2004.

9. Koizumi K, Kozawa Y, Ohashi Y, Nakamura ES, Aozuka Y, Sakurai H, Ichiki K, Doki Y, Misaki T and Saiki I: CCL21 promotes the migration and adhesion of highly lymph node metastatic human non-small cell lung cancer Lu-99 in vitro. Oncol Rep 17: 1511-1516, 2007.

10. Senda K, Koizumi K, Prangsaengtong O, Minami T, Suzuki S, Takasaki I, Tabuchi Y, Sakurai H, Doki Y, Misaki T and Saiki I: Inducible capillary formation in lymphatic endothelial cells by blocking lipid phosphate phosphatase-3 activity. Lymphat Res Biol 7: 69-74, 2009.

11. Cho S, Koizumi K, Takeno N, Kato S, Yamada M, Hashimoto I, Sakurai H, Tsukada K and Saiki I: Antitumor effect of combining CC chemokine 22 (CCL22) and an anti-CD25 antibody on myeloma cells implanted subcutaneously into mice. Mol Med Rep 2: 773-777, 2009.

12. Chada S, Ramesh R and Mhashilkar AM: Cytokine- and chemokine-based gene therapy for cancer. Curr Opin Mol Ther 5: 463-474, 2003.

13. D'Elios MM, Del Prete G and Amedei A: New frontiers in cell-based immunotherapy of cancer. Expert Opin Ther Pat 19: 623-641, 2009.

14. Bazan JF, Bacon KB, Hardiman G, Wang W, Soo K, Rossi D, Greaves DR, Zrotnik A and Schall TJ: A new class of membranebound chemokine with a CX3C motif. Nature 385: 640-644, 1997.

15. Imaizumi T, Yoshida H and Satoh K: Regulation of CX3CL1/ fractalkine expression in endothelial cells. J Atheroscler Thromb 11: 15-21, 2004.

16. Kanazawa N, Nakamura T, Tashiro K, Muramatsu M, Morita K, Yoneda K, Inaba K, Imamura S and Honjo T: Fractalkine and macrophage-derived chemokine: $\mathrm{T}$ cell-attracting chemokines expressed in T cell area dendritic cells. Eur J Immunol 29: 1925-1932, 1999.

17. Hundhausen C, Misztela D, Berkhout TA, Broadway N, Saftig P, Reiss K, Hartmann D, Fahrenholz F, Postina R, Matthews V, et al: The disintegrin-like metalloproteinase ADAM10 is involved in constitutive cleavage of CX3CL1 (fractalkine) and regulates CX3CL1-mediated cell-cell adhesion. Blood 15: 1186-1195, 2003.

18. Garton KJ, Gough PJ, Blobel CP, Murphy G, Greaves DR, Dempsey PJ and Raines EW: Tumor necrosis factor-alphaconverting enzyme (ADAM17) mediates the cleavage and shedding of fractalkine (CX3CL1). J Biol Chem 12: 37993-38001, 2001.

19. Yamaura T, Doki Y, Murakami K and Saiki I: Model for mediastinal lymph node metastasis produced by orthotopic intrapulmonary implantation of lung cancer cells in mice. Hum Cell 12: 197-204, 1999.

20. Yamaura T, Murakami K, Doki Y, Sugiyama S, Misaki T, Yamada Y and Saiki I: Solitary lung tumors and their spontaneous metastasis in athymic nude mice orthotopically implanted with human non-small cell lung cancer. Neoplasia 2: 315-324, 2000.

21. Ichiki K, Mitani N, Doki Y, Hara H, Misaki T and Saiki I: Regulation of activator protein-1 activity in the mediastinal lymph node metastasis of lung cancer. Clin Exp Metastasis 18: 539-545, 2000.

22. Vicari AP and Caux C: Chemokines in cancer. Cytokine Growth Factor Rev 13: 143-154, 2002.

23. Koizumi K, Hojo S, Akashi T, Yasumoto K and Saiki I: Chemokine receptors in cancer metastasis and cancer cell-derived chemokines in host immune response. Cancer Sci 98: 1652-1658, 2007. 
24. Ueno T, Toi M, Saji H, Muta M, Bando H, Kuroi K, Koike M, Inadera $\mathrm{H}$ and Matsushima K: Significance of macrophage chemoattractant protein-1 in macrophage recruitment, angiogenesis, and survival in human breast cancer. Clin Cancer Res 6: 3282-3289, 2000.

25. Luboshits G, Shina S, Kaplan O, Engelberg S, Nass D, LifshitzMercer B, Chaitchik S, Keydar I and Ben-Baruch A: Elevated expression of the $\mathrm{CC}$ chemokine regulated on activation, norma $\mathrm{T}$ cell expressed and secreted (RANTES) in advanced breast carcinoma. Cancer Res 59: 4681-4687, 1999.

26. Hojo S, Koizumi K, Tsuneyama K, Arita Y, Cui Z, Shinohara K, Minami T, Hashimoto I, Nakayama T, Sakurai $\mathrm{H}$, et al: High-level expression of chemokine CXCL16 by tumor cells correlates with a good prognosis and increased tumorinfiltrating lymphocytes in colorectal cancer. Cancer Res 15: 4725-4731, 2007.
27. Ohta M, Tanaka F, Yamaguchi H, Sadanaga N, Inoue H and Mori M: The high expression of Fractalkine results in a better prognosis for colorectal cancer patients. Int J Oncol 26: 41-47, 2005.

28. Hyakudomi M, Matsubara T, Hyakudomi R, Yamamoto T, Kinugasa S, Yamanoi A, Maruyama R and Tanaka T: Increased expression of fractalkine is correlated with a better prognosis and an increased number of both $\mathrm{CD}^{8+} \mathrm{T}$ cells and natural killer cells in gastric adenocarcinoma. Ann Surg Oncol 15: 1775-1782, 2008. 